\title{
Getting Costs Right in Global Surgery
}

\author{
Mark G. Shrime ${ }^{1,2}$ (1)
}

Accepted: 13 August 2021 / Published online: 26 August 2021

(C) The Author(s) 2021

In 2015, my colleagues and I estimated that over 80 million people each year experience financial catastrophe due to the costs of getting surgery [1].

This estimate and the resulting World Bank annual updates are the result of a model built on the best available evidence at the time. However, as George Box famously wrote, "All models are wrong, but some are useful," [2] a fact that is no less true of our catastrophic expenditure model. The biggest data deficit we face has been for out-ofpocket surgical costs, especially in countries in the global South [3].

This has begun to change, if slowly. Since 2015, 72 papers addressing the cost of surgery in lower-resource populations have been indexed on PubMed. The recent paper by Umo and James adds to this evidence [4]. The authors find that the total cost of surgery for an acute appendix in Papua New Guinea, including both hospitaland patient-level costs, ranges from US\$11,300 and US $\$ 13,300$. Of that, patients' hospital fees amount to only $\$ 124$. (For context, the per capita gross domestic product in the country is US\$2636 per year [5].)

This speaks volumes. First, it highlights the intricacies of costing. The authors chose a rather unconventional hospital-plus-patient perspective to their costing study. In doing so, however, they present an almost-complete picture of the overall cost the health system bears to deliver an appendectomy.

Mark G. Shrime

shrime@mail.harvard.edu

1 Institute of Global Surgery, Royal College of Surgeons in Ireland, Dublin, Ireland

2 Department of Global Health and Social Medicine, Harvard Medical School, Boston, USA
Choosing the correct perspective is important. When cost-effectiveness studies are undertaken, a societal costing perspective like the authors' is appropriate: outcomes like disability- and quality-adjusted life years are societal, so the costing must follow suit. On the other hands, studies of non-medical outcomes of surgical care, such as financial catastrophe, require a patient-level costing to be disentangled from the societal cost.

This also speaks volumes about the necessity of costing data to confirm or reject modeled estimates. In this case, the model is in line with what the authors find: The World Bank estimates that $3.8 \%$ of Papua New Guineas would face catastrophic expenditure if they needed surgery [5]. Using Umo and James's out-of-pocket costs, the estimate rises to $5.8 \%$ of the population of Papua New Guinea, with a $95 \%$ uncertainty interval $(1.7-12.4 \%)$ that includes the original.

With time, even the best models become less relevant. The risk of financial catastrophe due to surgery does not. Ongoing studies into patient- and system-level costs for surgery continue to be an imperative.

Funding Open Access funding provided by the IReL Consortium.

Open Access This article is licensed under a Creative Commons Attribution 4.0 International License, which permits use, sharing, adaptation, distribution and reproduction in any medium or format, as long as you give appropriate credit to the original author(s) and the source, provide a link to the Creative Commons licence, and indicate if changes were made. The images or other third party material in this article are included in the article's Creative Commons licence, unless indicated otherwise in a credit line to the material. If material is not included in the article's Creative Commons licence and your intended use is not permitted by statutory regulation or exceeds the permitted use, you will need to obtain permission directly from the copyright 
holder. To view a copy of this licence, visit http://creativecommons. org/licenses/by/4.0/.

\section{References}

1. Shrime MG, Dare AJ, Alkire BC, O’Neill K, Meara JG (2015) Catastrophic expenditure to pay for surgery worldwide: a modelling study. Lancet Glob Health 3(Suppl 2):S38-44

2. Box GEP, Draper NR (1987) Empirical model-building and response surfaces. Wiley, New York
3. Dados N, Connell R (2012) The global south. Contexts 11(1):12-13

4. Umo I, James K (2021) The direct medical cost of acute appendicitis surgery in a resource limited setting of Papua New Guinea. World J Surg. https://doi.org/10.1007/s00268-021-062902

5. World Bank. World Bank Data Catalog (2018) [cited 2019 Oct 3]. Available from: https://data.worldbank.org/

Publisher's Note Springer Nature remains neutral with regard to jurisdictional claims in published maps and institutional affiliations. 